\title{
Iatrogenic onycholysis
}

Zaouri H*, Elmakrini N, Squalli A, Berbich L, Senouci K and Hassam B

Department of Dermatology, Venereology, Ibn Sina Hospital University Rabat Morocco, Morocco

\begin{abstract}
Docetaxel is an antineoplastic agent. Several adverse effects of this agent molecule have been reported, including dermatological manifestations. Herein, we report a case of a 42 years-old man, followed for breast invasive ductal carcinoma with lung metastasis, treated by Docetaxel monochemotherapy, who presented a painful onycholysis, with nails discolorations and beau's lines.
\end{abstract}

\section{Introduction}

Docetaxel is an antineoplastic drug from the taxane family. Several adverse effects of this agent molecule have been reported. Herein, we report a new case of patient who presented a dermatological manifestations.

\section{Clinical case}

A 42 years-old man, followed for breast invasive ductal carcinoma with lung metastasis, treated by Docetaxel monochemotherapy, using a dose of $80 \mathrm{mg} / \mathrm{m} 2 / 21$ days, who presented a painful onycholysis of all the fingers and both big toes, with nails discolorations and beau's lines at some nails right after the 4th cure (Figures 1,2 and 3). We recommended a fortifyed varnish based on silicon, a moisturising and barrier cream with photoprotection. We also proposed for the next treatments, to wear frozen gloves and socks.

\section{Comments}

Docetaxel (Taxotere ${ }^{\star}$ ) is an alkaloid derived from yew needles of the taxane family. It's an antineoplastic agent that acts by promoting the assembly of tubulin into stable microtubules and inhibits their depolymerization, this leads to the interruption of mitosis and cell replication.

Several adverse effects of this agent molecule have been reported, including hematologic, gastrointestinal, neurological and dermatological manifestations. $60 \%$ of the patients experienced dermatological side effects such as limb erythematous reactions,

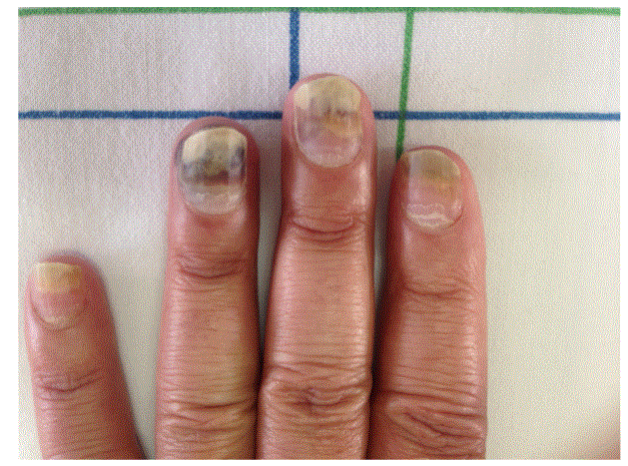

Figure 1. Onycholysis with nails discolorations and beau's lines. plaque-like erythrodysesthesia, erythema multiforme, nail changes, scleroderma, supravenous discoloration, radiation recall dermatitis, desquamation, and flagellate erythema and Stevens Johnson syndrome [1]. $30 \%$ of the patients using docetaxel experienced some kind of nail disorders [2], such as chromonychies, Beau's lines, bleeding under nail, felons and painful onycholyses. All nails may be affected, but especially

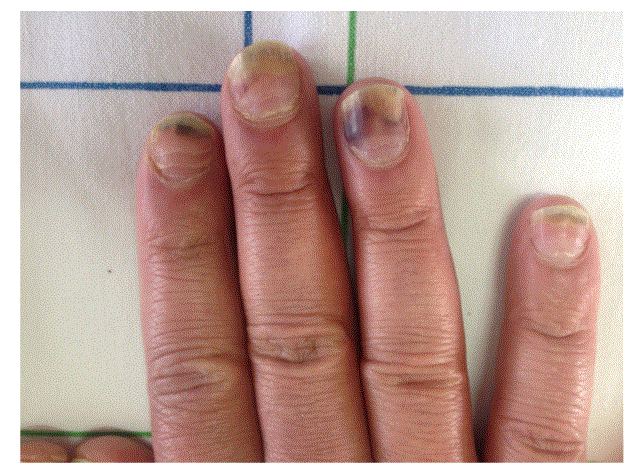

Figure 2. Onycholysis with nails discolorations and beau's lines.

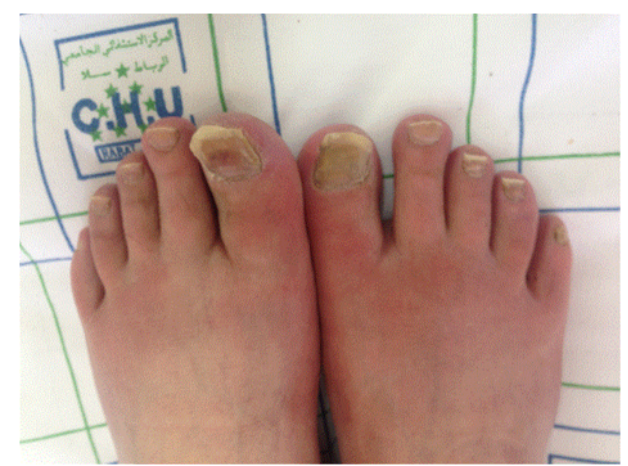

Figure 3. Onycholysis with nails discolorations and beau's lines.

Correspondence to: Zaouri H, Department of Dermatology, Venereology, Ibn Sina Hospital University Rabat Morocco, Morocco, Tel: 00212661223823; E-mail: hasnaazaouri@yahoo.fr

Key words: onycholysis, beau's lines, docetaxel

Received: March 10, 2017; Accepted: March 24, 2017; Published: March 27, 2017 
finger nails. These disorders are dependent on the doses prescribed and usually start to appear after the $3^{\text {rd }}$ cure of chemotherapy.

The physiopathology of the nail toxicity is unknown. It would be induced by direct toxicity of docetaxel on the various constituents of the nails, such as the matrix, the nail bed, the periungual tissue, or blood vessels [3]. Several studies have suggested that the anti-angiogenic properties of taxanes may be involved in the toxicity of the nail [4]. In most cases the nail involvement does not require a discontinuation of the treatment. Preventive treatment should be started from the first cycle of docetaxel, this particularly include the use of refrigerated gloves and socks during the administration of chemotherapy [2], the application of a nail varnish containing silicon up to 3-6 months after the end of chemotherapy, with a moisturizing periungual.

This observation underlines the interest to better know this rare side effect, for better prevention.

\section{Conflict of interests}

None.

\section{References}

1. Marijon E, Grasland A, Grandjean M, Pouchot J, Vinceneux P (2002) Onycholysesecondaire à un traitement par docétaxel. La Revue de Médecine Interne 8663: 80367-80368.

2. Scotté F, Tourani JM, Banu E, Peyromaure M, Levy E, et al. (2005) Multicenter Study of a Frozen Glove to Prevent Docetaxel-Induced Onycholysis and Cutaneous Toxicity of the Hand. J Clin Oncol 23:4424-4429.

3. Piraccini BM, Iorizzo M, Antonucci A, Tosti A (2004) Drug-induced nail abnormalities. Expert Opin Drug Saf 3: 57-65.[Crossref]

4. Spadaro P, Maisano R, Mare M (2002) Is there any correlation between decreased serum vas-cular endothelial growth factor (sVEGF) levels and nail toxicity in responsive metastatic breast cancer (MBC) patients treated with weekly docetaxel. Preliminary data of a phase II study. Proc Am Soc Clin Oncol P. 20.

Copyright: (C2017 Zaouri H. This is an open-access article distributed under the terms of the Creative Commons Attribution License, which permits unrestricted use, distribution, and reproduction in any medium, provided the original author and source are credited. 